INDEPENDENT JOURNAL OF MANAGEMENT \& PRODUCTION (IJM\&P)

\title{
SIMULATION OF OPERATIONAL PROCESSES IN HOSPITAL EMERGENCY UNITS AS LEAN HEALTHCARE TOOL
}

\author{
Andreia Macedo Gomes \\ Centro Federal de Educação Tecnológica Celso Suckow da \\ Fonseca, Brazil \\ E-mail: andreiamg@hotmail.com
}

Pedro Senna Vieira Centro Federal de Educação Tecnológica Celso Suckow da Fonseca, Brazil E-mail: pedro.sennavieira@gmail.com

Augusto da Cunha Reis Centro Federal de Educação Tecnológica Celso Suckow da Fonseca, Brazil E-mail: acreis_1@yahoo.com.br

Submission: 03/01/2017 Accept: 15/01/2017

\section{ABSTRACT}

Recently, the Lean philosophy is gaining importance due to a competitive environment, which increases the need to reduce costs. Lean practices and tools have been applied to manufacturing, services, supply chain, startups and, the next frontier is healthcare. Most lean techniques can be easily adapted to health organizations. Therefore, this paper intends to summarize Lean practices and tools that are already being applied in health organizations. Among the numerous techniques and lean tools used, this research highlights the Simulation. Therefore, in order to understand the use of Simulation as a Lean Healthcare tool, this research aims to analyze, through the simulation technique, the operational dynamics of the service process of a fictitious hospital emergency unit. Initially a systematic review of the literature on the practices and tools of Lean Healthcare was carried out, in order to identify the main techniques practiced. The research highlighted Simulation as the sixth most cited tool in the literature. Subsequently, a simulation of a service model of an emergency unit was performed through the Arena software. 
INDEPENDENT JOURNAL OF MANAGEMENT \& PRODUCTION (IJM\&P)

http://www.ijmp.jor.br

v. 8, n. 5, Special Edition IFLOG 2016

ISSN: 2236-269X

DOI: 10.14807/ijmp.v8i5.607

As a main result, it can be highlighted that the attendants of the built model presented a degree of idleness, thus, they are able to attend a greater demand. As a last conclusion, it was verified that the emergency room is the process with longer service time and greater overload.

Keywords: Simulation, Lean Healthcare.

\section{INTRODUCTION}

Faced with increased competitiveness and inability to meet demands, health organizations are increasingly seeking structural and organizational changes with the goal of achieving improvements in their performance. The implementation of the Lean methodology in health care facilities, known as Lean Healthcare, has been a growing alternative in search of quality, based on patient needs and resource savings. According to Cheng et al. (2015), the application of Lean in health services over the last decade has been associated with increased quality, safety, and efficiency through improved clinical processes.

In serach of adopt the Lean philosophy in health services, many organizations have adopted various approaches and strategies for improvement. There are a variety of tools and techniques that can be used by health organizations in this regard. Aguila-Escobar \& Garrido-Vega (2012) discussed the applicability of Lean principles in the management of the supply chain of a hospital through the implementation of the Kanban system. McClean et al. (2007) showed the use of the Markov Model to identify more efficient patient paths in a hospital that could be associated with health process improvement technologies such as Lean Thinking and Six Sigma. Another approach was suggested by DiGioia et al. (2015) who proposed the integration of two approaches, adding the methodology "Patient and Family Centered Care Methodology and Practice" (PFCC M / P) to the Lean filosophy. According to the authors, integrating the two approaches can address the needs of keeping the patient (and family) as the primary focus of improvement activities in addition to accelerating the pace of improvements.

The Lean philosophy has been widely studied and implemented in many different contexts. With this growing interest in this approach, new tools and techniques have emerged, inspired by the production systems of various industries. Increasingly, these techniques have been introduced into the hospital environment in 
an attempt to achieve better performance. Among the many techniques and tools used in the adoption of the Lean philosophy in health units, we can cite Simulation.

Robinson et al. (2012) report a long historical trajectory of the use of simulation in the health area, noting that Lean and Simulation seem to be a potential still little appreciated in the health services. In this way, the author tried to emphasize that there is a symbiotic relationship between Simulation and Lean, describing how the two approaches can be fused through an approach called "SimLean" by the author, showing the complementarity between both.

Pinto (2001) suggests the use of models that use Simulation and Optimization concepts simultaneously, associating the objectives of the optimization to the advantages of the Simulation, that is, it is possible to determine the "optimal objective" of a simulation model including probabilistic aspects, through the use of non deterministic or stochastic variables.

In this context, there was a need to understand the application of the Simulation tool as a Lean Healthcare approach, with the purpose of knowing the improvements that this tool can provide in health services. Against the foregoing, this work aims to analyze, through the Simulation technique, the operational dynamics of the service process of a fictitious hospital emergency unit.

\section{METHODOLOGY}

This research was performed in two phases. The first phase consisted of a systematic review of the literature about techniques and tools used in the Lean Healthcare approach, with he objetctiv of identify the main techniques used, among them the simulation. The second phase consisted of an application of the Simulation in the operational processes in a fictitious emergency hospital unit.

Thus, this research is classified, in its initial phase, as a bibliographical research and, in the second phase, can be classified as an applied research, in terms of the objectives as a descriptive research and in the approach as a quantitative research.

The systematic review requires a rigorous methodological framework, therefor, the content analysis represents an effective tool for analyzing a sample of research documents in a systematic way and with strict rules (Seuring and Gold, 
2012). The model proposed by Seuring and Gold (2012) for conducting systematic review through content analysis consists of 4 steps:

1. Material Collection,

2. Descriptive analysis,

3. Category Selection, and

4. Material evaluation.

The first step came from complete search of publications performed through survey of bibliographic productions in the SCOPUS database, using the term "Lean Healthcare". The search took place in August 2015, and a total of 612 publications were found. Then, an initial screening of the publications found was performed through the verification of titles and abstracts, in order to discard those that did not fall within the scope of this research. The inclusion criteria were articles dealing with the topic Lean Healthcare in Portuguese or English. To organize the publications, the management reference tool Mendeley Desktop was used.

The second step consisted in the fluent reading of the texts and abstracts in which the central idea of the articles was delimited in order to identify which Lean tools were used by the authors. In this step incomplete articles (summaries only) that did not contain sufficient information to identify which Lean technique or Lean tool was used were excluded.

In the third step a categorization of the literature based on criteria was done as shown in the conceptual model created in figure 1, the classification criteria are divided into three main blocks, which are divided into subcategories. The categories are detailed below:

1- General information of the article: Based on the information collected, analyzes were made regarding the year of publication, most relevant journals and the main authors.

2 - Research method: papers were classified as conceptual or practical / applied. In conceptual ones, fit those article that seek to critically evaluate recent production about Lean Healthcare theme. They are the literature reviews. In the practical / applied papers can be considered case studies and reports of experiences. 
3- Approach: tools and techniques identified in the articles were classified in quantitative and qualitative. In the quanlitative category, techniques and tools of a subjective character were considered and in the quantitative category, the numerical techniques and tools were considered.

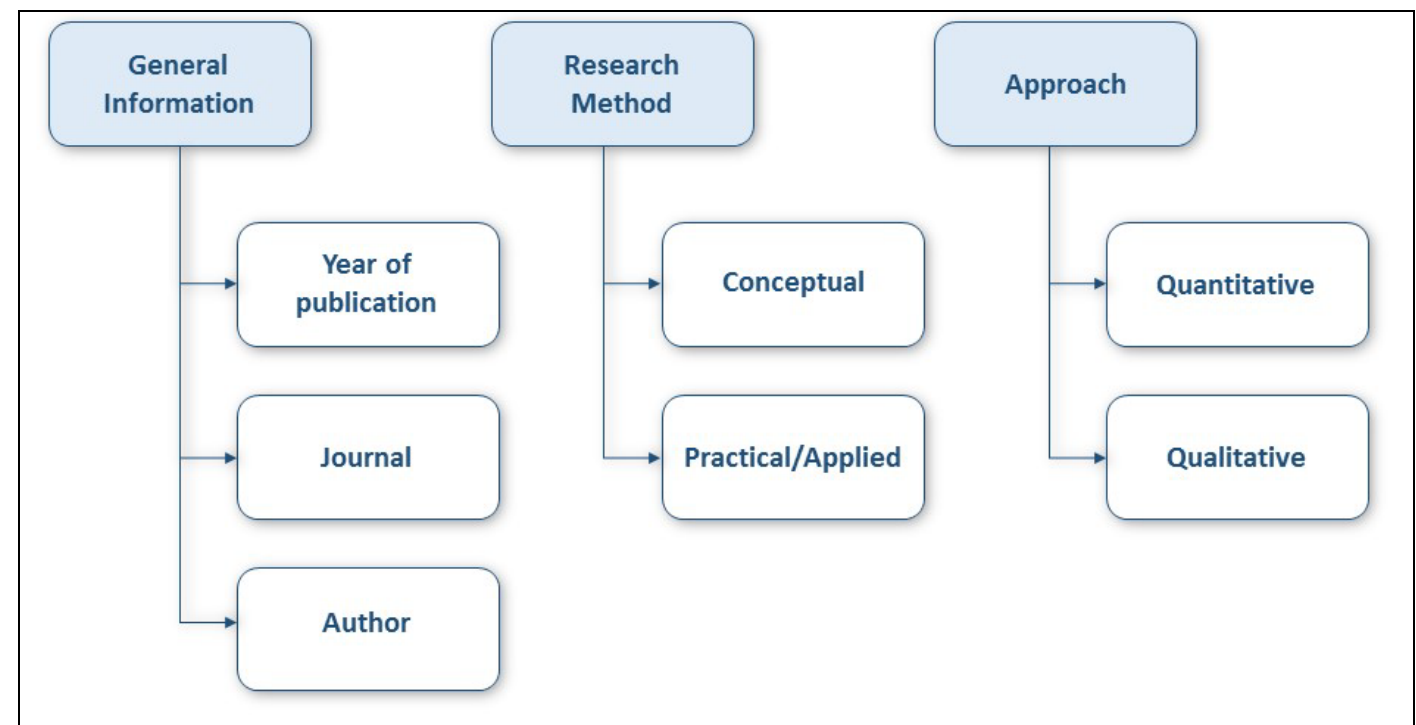

Figure 1: Conceptual model of the systematic review of the literature. Source: prepared by the authors

In the fourth step the evaluation of the selected material was carried out. The article sample was evaluated according to the criteria mentioned above. The categorization process was based on the authors' academic judgment.

For the second phase of this study, as a research strategy, the Simulation tool for a fictitious hospital emergency unit was used, in order to illustrate the approach. The flow modeling and emergency processes presented in this research was referenced by model studied by Ely (2009), but for the purpose of this research was chosen to represent the model in a simplified way. For the simulation, Arena software was used. From the definition of the system to be simulated, it was possible to construct a conceptual model of the studied process that provided information to the computational model. The conceptual model was represented as a flowchart as shown in figure 2. 


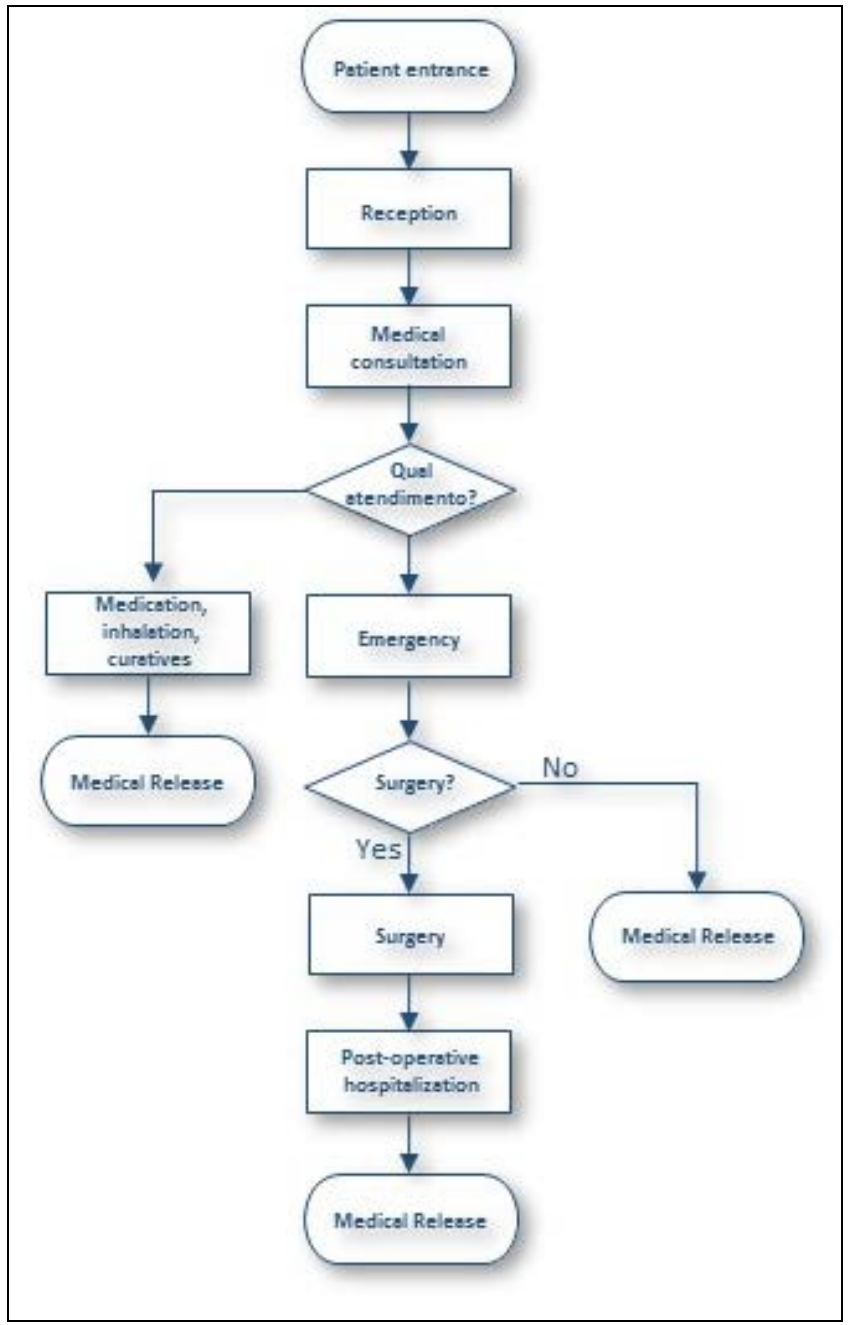

Figure 2: System flowchart

Source: prepared by authors

The choice of frequency distribution for each workstation in the above flow was based on the best application of the available distributions in the Arena according to Prado (2004), where the exponential distribution was used for the arrival of patients and the triangular distribution for attendance. The variables analyzed were waiting time for each service and queue time.

\section{RESULTS}

\subsection{Systematic Review of Literature on Lean Healthcare Techniques and} Tools

Following the research method described above, in the first phase that consisted of a systematic literature review, a total of 612 potentially relevant articles were found. After the initial screening, articles that did not fit the scope of the research were excluded, as well as repeated articles, resulting in a total of 213 articles, of which 109 were summaries and 104 complete publications. 
After reading fluently the texts and abstracts, 38 incomplete articles were not included, which did not present enough information to identify the applied Lean technique or tool, totaling 175 articles between 2002 and 2015, of which 66 summaries and 109 complete publications. Figure 3 shows a summary of the strategy of the article selection process.

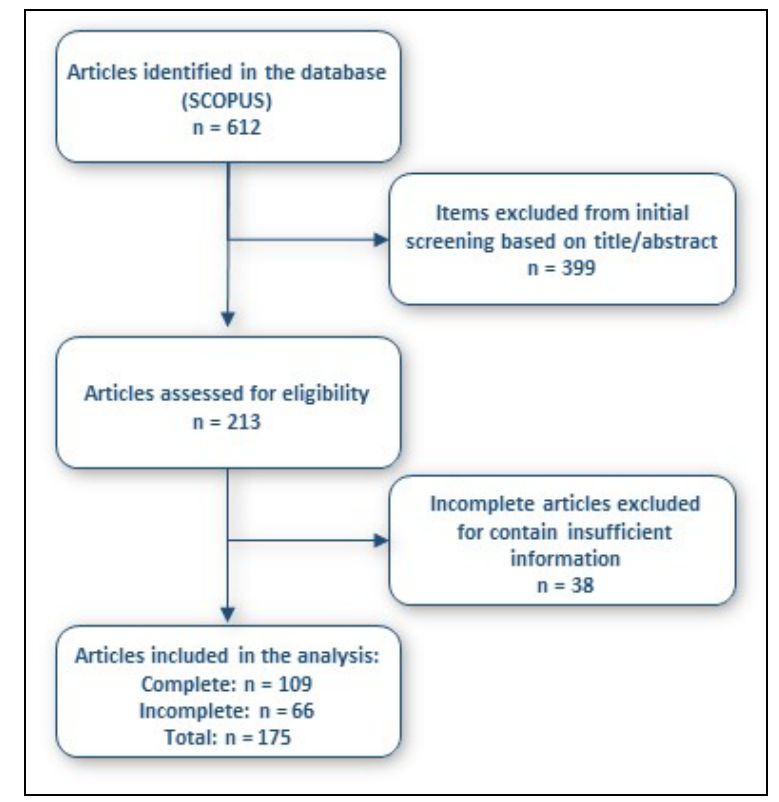

Figure 3: Strategy summary of the article selection process.

Source: prepared by outhors

The sample of articles covers publications from 2002 to 2015. A growing trend has been identified in the number of publications over the period, with very few publications being observed in the early years, and their apex occurred in 2014. By the date of construction of this article, 24 publications were found in 2014. Considering that the year 2015 had not yet ended, there is an estimated increase in the number of publications for this year. An illustration of the distribution of publications per year can be seen in figure 4 .

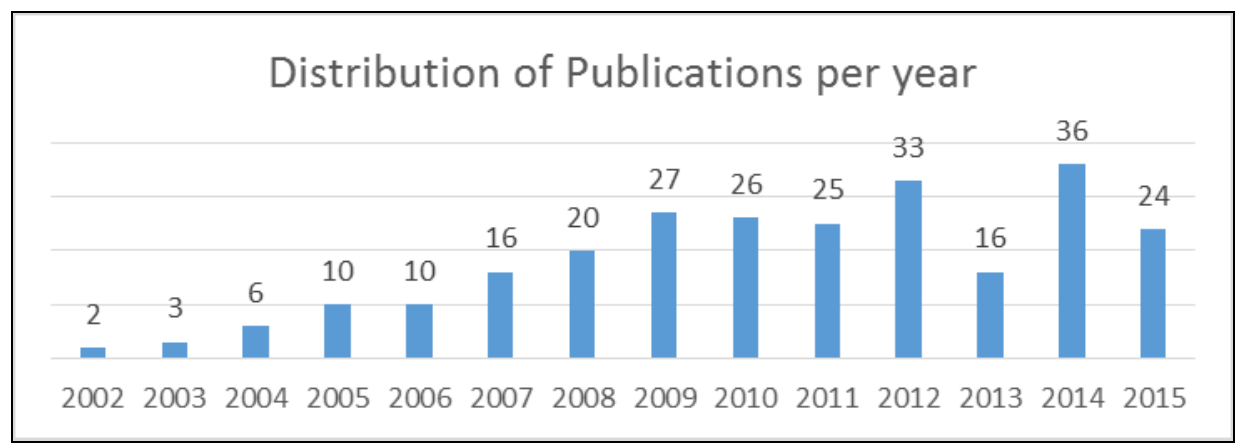

Figure 4: Distribution of publications per year 
The most relevant journals were identified for this search, as shown in Figure 5. The journals in which the largest number of articles with the Lean Heathcare subject were found were the International Journal of Leann Six Sigma and Competitive Advantage and the Journal for Healthcare Quality, both with 8 publication founded.

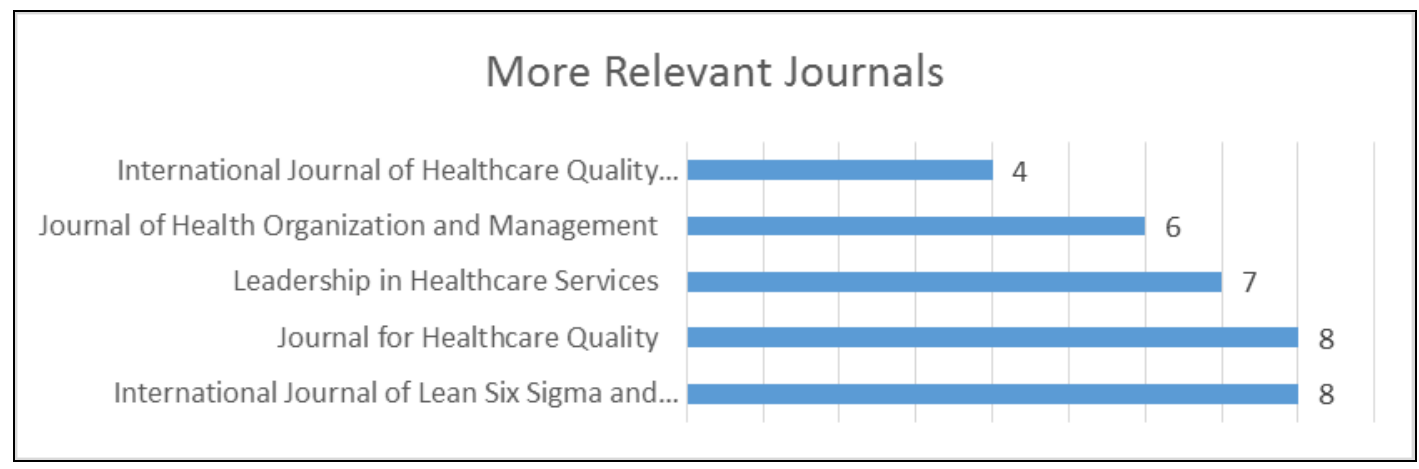

Figure 5: more relevant journals founded in research

Table 1 classifies authors with at least 3 published articles. Two authors presented the largest number of publications and only one author presented 3 publications in the area of Lean Healthcare (PAPADOPOULOS, 2011; PAPADOPOULOS, et al., 2011; PAPADOPOULOS; MERIAL, 2009).

Table 1: Authors rank with at least three publications

\begin{tabular}{lccl}
\hline \multicolumn{1}{c}{ Author } & Articles & Afiliation & Country \\
\hline Thanos & 4 & Universit of Southampton & UK \\
Papadopoulos & & & \\
Matt Morissette & 4 & More Effective Consulting & USA \\
Nicolo Curatolo & 3 & Arts et Metiers Paris Tech & France \\
\hline
\end{tabular}

In all, 56 different techniques or tools were used in the implementation of Lean Healthcare. As can be seen in the graph of Figure 6, there is a wide variety of Lean tools and techniques found in the researched literature. Despite the large number of techniques mentioned, few of them were mentioned in the articles included in this review. The most used techniques by the authors were Six Sigma, Value Stream Mapping (VSM), Kaizen, 5S, process improvement / mapping, simulation and PDCA / PDSA, with the most cited Six Sigma technique. About 27 Lean tools were cited only once. 


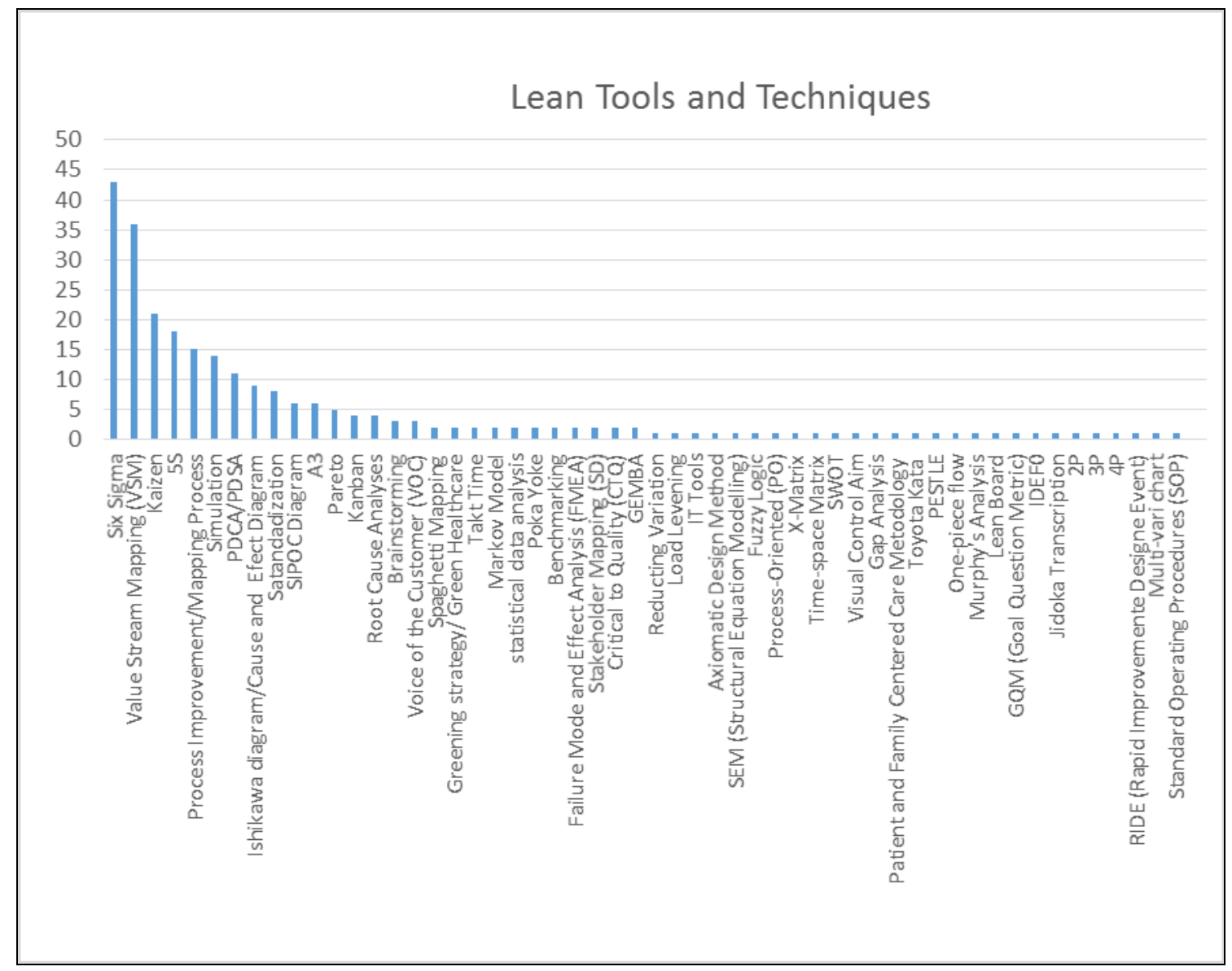

Figure 6: Lean tecniques and tools founded

The graph of the articles distribution by search method can be visualized in figure 7. As can be observed, the results show that there is a predominance of publications classified as practical / applied. Most publications in this category feature one or more case studies or experience reports for illustration of the Lean Healthcare application.

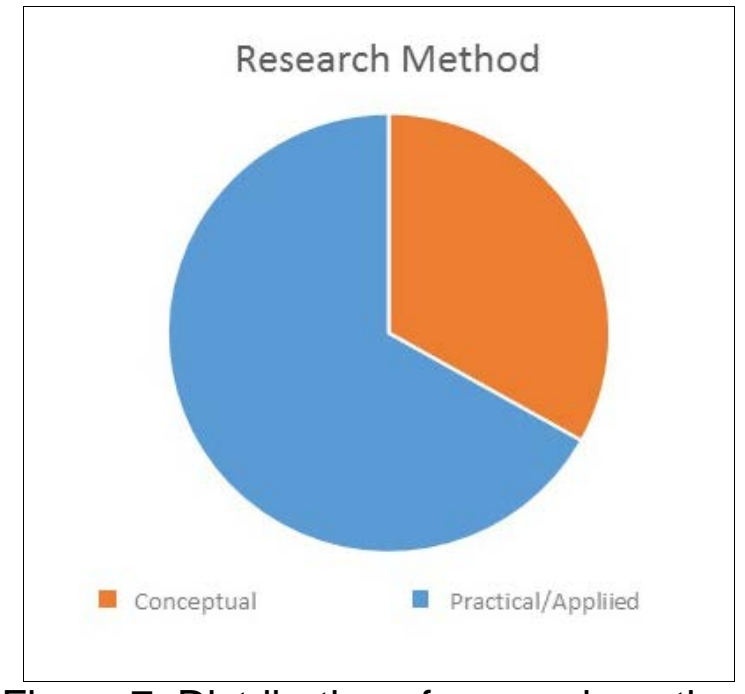

Figure 7: Distribution of research method 
The tools and techniques identified in this review were categorized as to the type of approach in quantitative and qualitative. Of the 54 techniques identified, 13 were classified as quantitative and 41 as qualitative. Figure 8 shows the distribution of the quantitative tools, with the Six Sigma tool being predominant, cited by 43 articles, and Figure 9 shows the distribution of the qualitative tools, with the Value Stream Mapping (VSM) technique being predominant, with 36 occurrences.

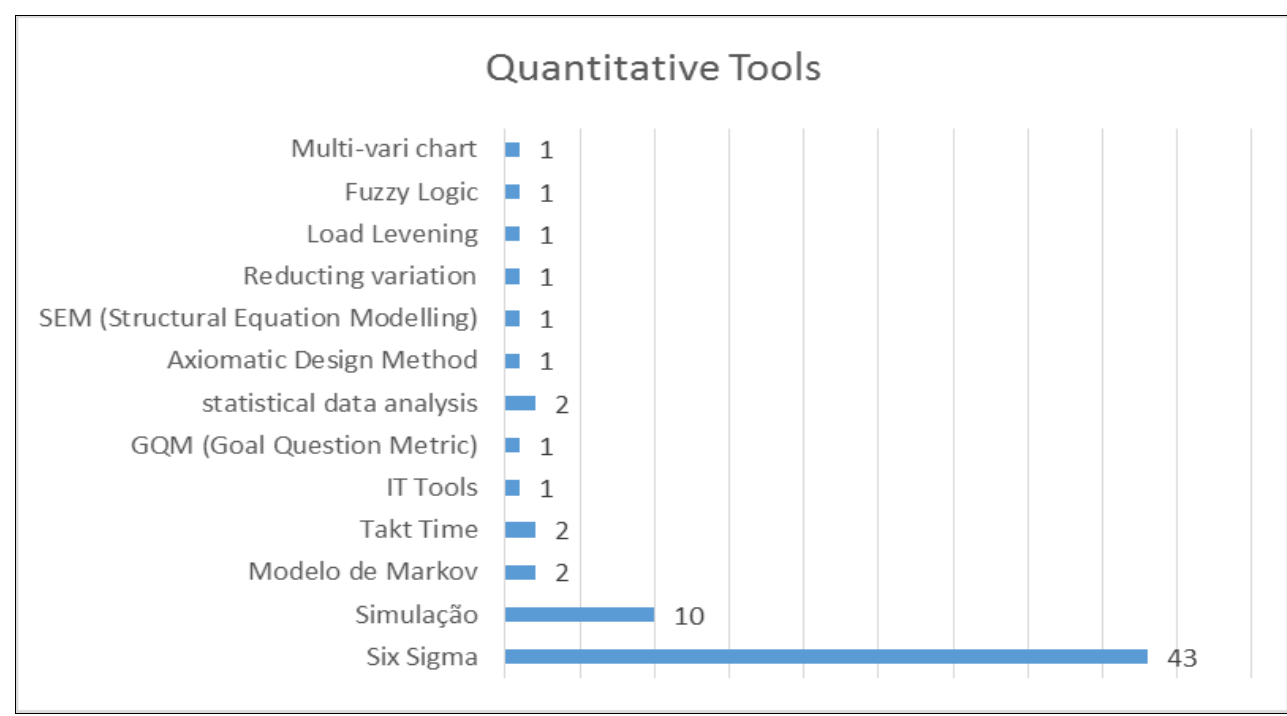

Figure 8: Distribution of quantitative tools

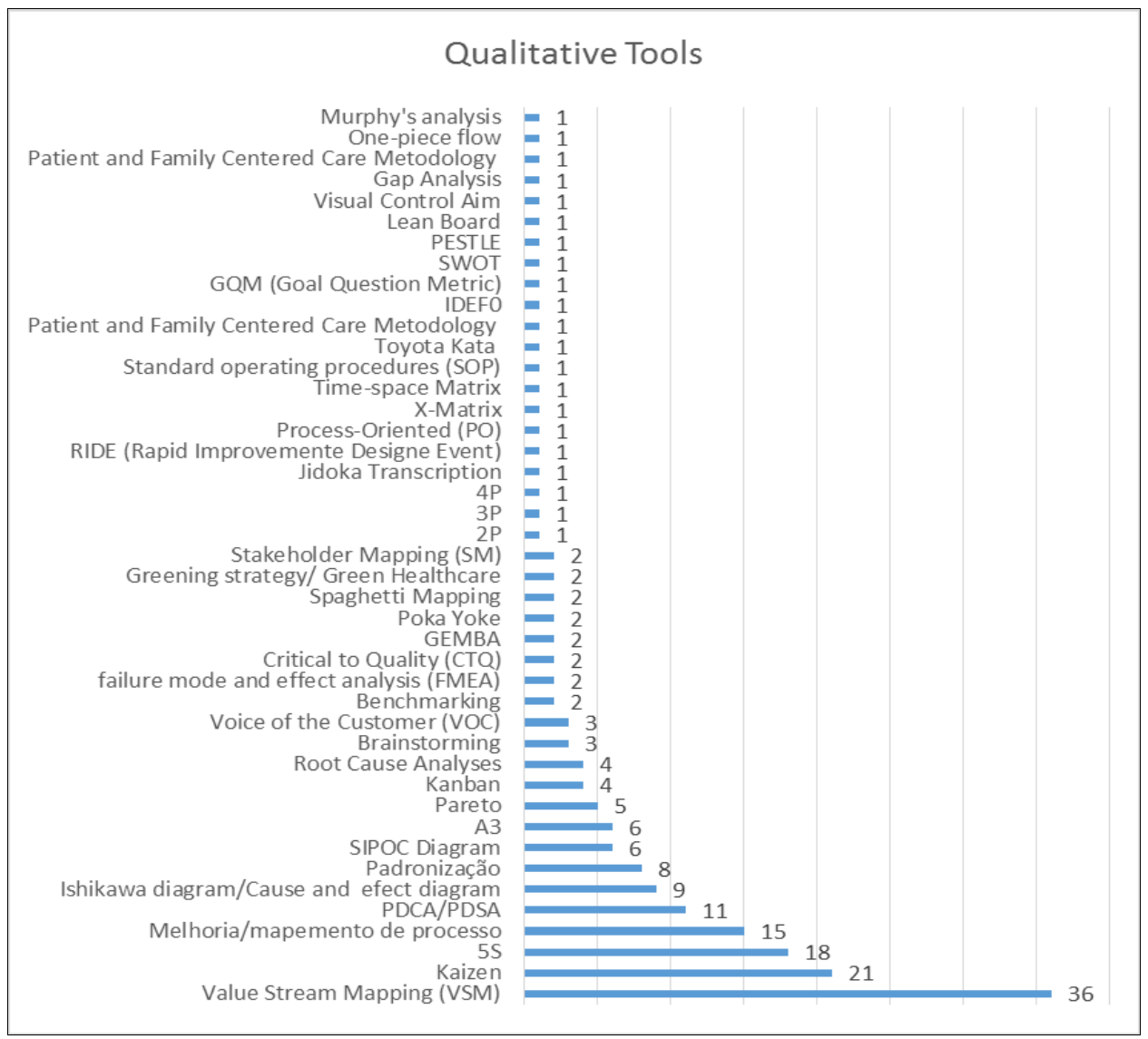

Figure 9: Distribution of qualitative tools 
Figure 10 shows a model with a summary of the main techniques and tools found in the literature.

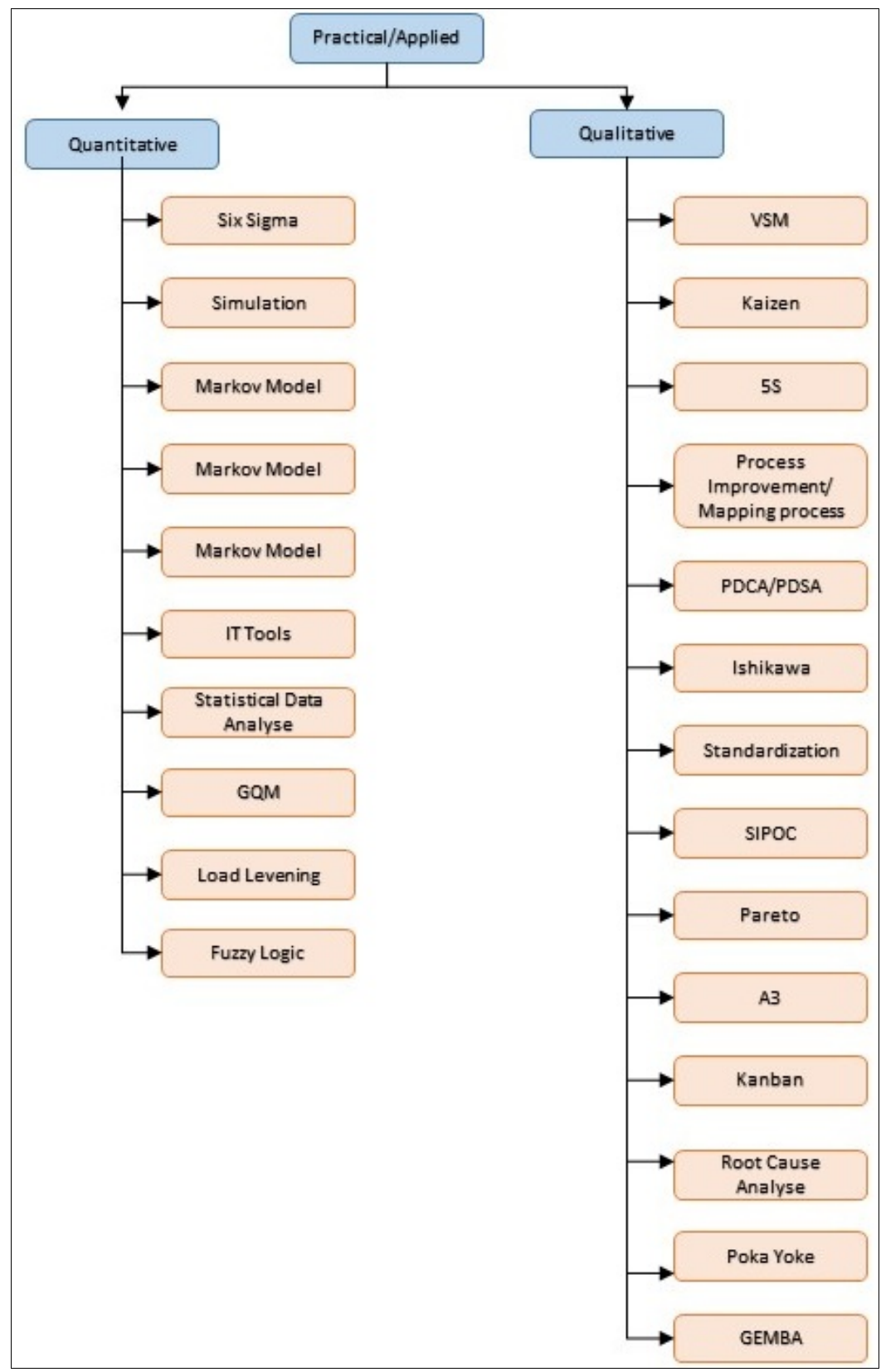

Figure 10: Summary model of the main Lean tools identified in the literature.

\subsection{Simulation of an Emergency Care Flow Model}

As previously reported in the study of systematic literature review, among the Lean tools identified in the literature, the Simulation technique was the second classified tool most cited by the authors. In this research, this tool was chosen for application. 
For the simulation, throughout this work, a fictitious model very close to an real application was used. Thus, for this example, a simple emergency sector was devised to validate the capabilities of the components created and identify possible improvements. Figure 11 represents the simulation model built in the Arena software.

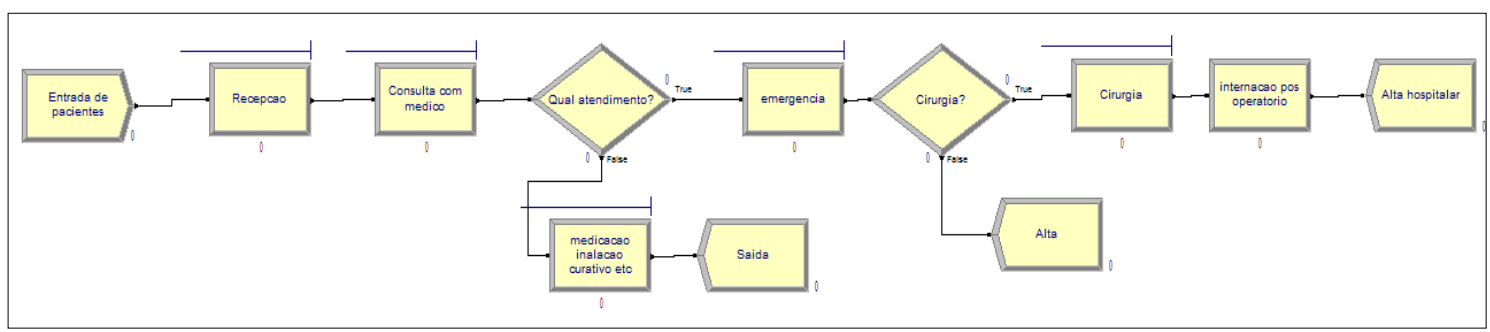

Figure 11: Simulation model Source: Prepared by authors

In an emergency unit, care is taken intermittently to the population, and the different sizes of emergency rooms of greater complexity should be defined according to the regional realities and the needs of the population (CALIL, 2007). After the immediate care, the flow of emergency care often goes beyond the emergency sector of the unit, requiring referral to other sectors of the hospital, as a surgical center, in order to continue the care. In this way, the model constituted in this research is a model of lower complexity, consisting of reception, medical office, medicine and curative sector, emergency care sector, surgical center and postoperative hospitalization sector.

The flow of care occurs as follows: patients arrive at service by random way and are atended at the reception desk, where they are referred to a waiting room to wait for the doctor's care. During the medical visit, the patient is evaluated and will be referred to the next care, which can be simple procedures such as administration of medicines or simple curative or, if necessary, may be a more complex emergency service that needs to be performed exams, requiring referral to the emergency care sector. If necessary, the patient may need more complex assistance such as emergency surgeries, in this case, then the patients are referred to the surgical center and later to the postoperative hospital.

The simulation of the operational dynamics of the emergency model prepared for this research was performed using the Arena software. A period of 1440 minutes ( 1 day) was simulated and 100 replications were performed, considering a warm-up 
time of 60 minutes and a 24-hour working day. The results of the simulation generated reports that will be described as follows:

- Attendance: an average of 67 patients were seen in the simulated period.

- Patient entry: an average of 92 patients entered the system.

- Patients in care: on average, about 17 patients were in attendance at the end of the simulation.

- Queue time: waiting time of, on average, 0.6421 hours (about $38 \mathrm{~min}$ ).

- Time of service: the patient stays on average 0.8372 hours (about $50 \mathrm{~min}$ ) in care throughout the process.

- Total time in the process: the patient took an average of 1.4793 hours to go through the process.

The Table 2 shows the total time the patient takes being treated within the system per process. As can be seen in Table 2, the processes with the highest average time of care were emergency and postoperative. Table 3 shows the instantaneous use of the resources during the simulation. The most used resource was the Emergency Team, followed by the Surgical Team and Postoperative Team.

Table 2: Total time per entity

\begin{tabular}{lcccc}
\hline Process & $\begin{array}{l}\text { Avarage } \\
\text { (hours) }\end{array}$ & $\begin{array}{l}\text { Minimum } \\
\text { (hours) }\end{array}$ & Value & $\begin{array}{l}\text { Maximum } \\
\text { (hours) }\end{array}$ \\
\hline Reception & 0,0515 & 0,00 & 0,7253 \\
Doctor's office & 0,0764 & 0,00 & 0,9588 \\
Emergency & 5,7734 & 0,00 & 18,2001 \\
Medication, etc. & 0,1137 & 0,00 & 1,8563 \\
Surgery & 1,7663 & 0,00 & 11,5909 \\
Postoperative & 4,1383 & 0,00 & 16,9334 \\
\hline
\end{tabular}

Source: prepared by authors

Table 3: Instantaneous use of resources

\begin{tabular}{lccc}
\hline Processo & $\begin{array}{c}\text { Avarage } \\
\text { (\%) }\end{array}$ & Minimum Value (\%) & Maximum Value (\%) \\
\hline Front desk clerk & 46,48 & 0,00 & 100 \\
Doctor & 62,22 & 0,00 & 100 \\
Emergency Team & 97,70 & 0,00 & 100 \\
Nursing & 62,22 & 0,00 & 100 \\
Surgical Team & 82,15 & 0,00 & 100 \\
Postoperative Team & 81,31 & 0,00 & 100 \\
\hline
\end{tabular}

Source: prepared by authors 
DOI: 10.14807/ijmp.v8i5.607

\section{DISCUSSION}

In the emergency work environment, time is limited, activities are numerous, and the clinical situation of users requires professionals to do everything to keep them from death risk, so the process is shaped in the fight against time to The reach of the vital balance (ELY, 2009).

However, in the analysis of the data of the proposed simulation, it is noticed that about 8 patients entered the system and did not finish service. It is considered that these patients were lost in the course of some process, supposing that they abandoned or, in other cases, they died during the service. This can be observed when we analyzed that exist about 67 patients completed care and 17 ones are in process at the end of the simulation, totalizing 84 patients. However, about 92 patients entered the system, verifying that 8 patients were lost.

Another point that should be emphasized is the time spent at reception attendance. The data obtained through the simulation showed, as can be observed in Table 2, an average reception time of 0.0515 (about $3.09 \mathrm{~min}$ ), which is not a limitation of the process, since it allows a satisfactory flow of Entry of patients into the system. However, as can be seen in table 3, the instantaneous utilization rate of the reception resource (receptionist) is $46.48 \%$. That is, there is underutilization of this resource, and it is found that the reception is able to attend a larger number of patients.

In the emergency room, as shown in table 2, the greatest time of patient care was verifying. This fact was also observed in the research conducted by Arcanjo and Amaral (2015) in an emergency unit. The authors argue that many people arrive for emergency care with symptoms such as headache, toothache, stomach pain, feverish state, among others, that could be treated at health posts. Thus, it ends up making the system of care overloaded and consequently compromising the level of attention that should be given to patients.

Fact also reported by Ely (2009) in his study of flow work processes in an emergency and emergency service. The author states that during her study it was frequent to see people who use the door of urgency and emergency not only for acute cases, but also in an elective way, to complement the attendances of the Basic Health Units and the specialized units. 
In the model proposed in this research, we can highlight the overload in the emergency process when analyzing the high instantaneous utilization rate of the Emergency Team resource, which, as shown in table 3, is $97.70 \%$. However, it was possible to verify through the analysis of the instantaneous utilization rate of all the resources of the studied model that, in a general way, the attendants of the model presented a degree of idleness. Thus, they are able to meet a greater demand than the one designed for this simulation.

\section{CONCLUSION}

The purpose of this research is to understand how to model processes for applying the simulation as a Lean tool. In this way, this research allowed the understanding of how to describe and simulate processes and flows of an emergency service through Arena software. The idea of this research is that the simulation of this dummy model can serve as a learning tool both to model processes and flows and how to use the mentioned simulation software.

It was also possible to understand, through the literature review, how the simulation is inserted in the range of tools and techniques of Lean Healthcare, being a tool widely used for process improvement.

The simulation of the proposed model allowed to identify the processes that can be considered as bottlenecks of the system and to identify points that can be improved in the processes of the studied system. Given this, this proposed model provided greater knowledge and learning of how to interpret the generated data of a simulation, being a basis for future applications in real models.

\section{ACKNOWLEDGMENTS}

Thanks to CNPq and CEFET-RJ for the financial support and granting of scientific research initiation grants.

\section{REFERENCES}

AGUILAR-ESCOBAR, V. G.; GARRIDO-VEGA, P. (2013) Gestión Lean en logística de hospitales: estudio de un caso. Revista de Calidad Asistencial, v. 28, n. 1, p. 42-49, 2013.

ARCANJO, C. F. D.; AMARAL, T. M. (2016) Mapeamento de fluxo de pacientes e simulação de eventos discretos no sistema público de saúde: um caso prático em uma unidade de pronto atendimento em Juazeiro - BA. In: XXXV Encontro

Nacional de Engenharia de Produção. Fortaleza, CE, 13 a 16 de outubro de 2016. 
CALIL, A. M. (2007) Estrutura Organizacional de um Serviço de Emergência. In: CALIL, A. M.; PARANHOS, W. Y. O Enfermeiro e as Situações de Emergências. São Paulo: Atheneu.

CHENG, S.; BAMFORD, P. M.; DEHE, B. (2015) Improving access to health services - challenges in Lean application. International Journal of Public Sector Management, v. 28, p. 121-135.

DIGIOIA, A. M.; GREEHOUSE, P. K.; CHERMAK, T.; HAYDEN, M. A. (2015) A case for integrating the Patient and Family Centered Care Methodology and Practice in Lean healthcare organizations. Healthcare.

ELY, D. (2009) Fluxos e Processos de Trabalho em um Serviço de Urgência e Emergência da Região Metropolitana de Porto Alegre. Trabalho de Conclusão de Curso de Especialização, Universidade Federal do Rio Grande do Sul, Porto Alegre.

MCCLEAN, S.; GARG, L.; MEENAN, B.; MILLARD, P. (2007) Using Markov Models to find Interesting Patient Pathways. Proceedings - IEEE Symposium on ComputerBased Medical Systems.

PAPADOPOULOS, T. (2011) Continuous improvment and dynamic actor associations: a study of Lean Thinking implementation in the UK National Health Service. Leadership in Health Service, v. 24, n. 3, p. 207-227.

PAPADOPOULOS, T.; MERIALI, Y. (2009) Stakeholder dynamic the implementation of process innovation: the case of Lean thinking in a UK NHS hospital trust. International Journal of Healthcare Tecnology \& Management, v. 10, n. 4, p. 303-324.

PAPADOPOULOS, T.; RADNOR, Z.; MERIALI, Y. (2011) The role of actor associations in understanding the implementation of Lean thinking in healthcare. International Joural of Oparations \& Production Management, v. 31, n. 2, p. 167191.

PINTO, J.; ORLANDO P. F. (2001) Simulação e otimização; Desenvolvimento de uma ferramenta de análise de decisão para suprimento de refinarias de petróleo através de uma rede de oleodutos. Dissertação de mestrado em engenharia de produção. UFSC. Florianopolis.

PRADO, D. S. (2004) Usando o Arena em Simulação. INDG Tecnologia e Serviços Ltda., Belo Horizonte, MG. v. 3, $2^{\mathrm{a}}$ edição.

ROBINSON, S.; RADNOR, Z. J.; BURGESS, N.; WORTHINGTON, C. (2012) SimLean: Utilising simulation in the implementation of lean in healthcare. European Journal of Operational Research, v. 219, n. 1, p. 188-197.

SEURING, S.; GOLD, S. (2012) Conducting content-analysis based literature reviews in supply chain management. Supply Chain Management: An International Journal, v. 17, n. 5, p. $544-555$. 